\title{
Performance enhancement of spherical natural graphite by phenol resin in lithium ion batteries
}

\author{
Yu-Shiang $\mathrm{Wu}^{\mathrm{a}, *}$, Yi-Hsiung Wang ${ }^{\mathrm{b}}$, Yuan-Haun Lee ${ }^{\mathrm{b}}$ \\ a Department of Mechanical Engineering, China Institute of Technology, Taipei 115, Taiwan, ROC \\ ${ }^{\mathrm{b}}$ Graduate Institute of Material Science and Engineering, National Taiwan University, Taipei 106, Taiwan, ROC \\ Received 11 May 2005; accepted 17 November 2005 \\ Available online 27 March 2006
}

\begin{abstract}
The capacity of natural graphite in the lithium ion battery anode decays seriously. The phenol resin is used as a reaction material to modify the electrochemical performance of spherical graphite as the anode material in lithium ion batteries. Measuring the reversible capacity indicates change in the surface structure of spherical graphite. A dense layer of methyl groups was thus formed. Some structural imperfections are removed and the stability of the graphite structure is increased. Clearly, reducing the irreversible capacity is beneficial in controlling the uniformity of the spherical graphite surface structure.
\end{abstract}

(C) 2006 Elsevier B.V. All rights reserved.

Keywords: Spherical natural graphite; Phenol resin; Lithium ion battery; Anode material

\section{Introduction}

Lithium ion batteries have several advantages over traditional rechargeable batteries and they have advanced very rapidly since their original development at the end of the 1980s and in the early 1990s. Of various carbon materials, graphite becomes the preferred anode electrode material due to its theoretical capacity of $372 \mathrm{mAh} / \mathrm{g}$, a low and smooth voltage curve and low cost. Although numerous anode materials have been investigated, graphite remains the preferred one.

Graphite has a spherical morphology that favors the passing of lithium ions. Spherical natural graphite is preferred as the anode electrode material. However, its severe capacity decay may limit its future utilization. In batteries, lithium ion intercalation and de-intercalation reduce the performance and lifetime of the battery. Therefore, the surface modification of spherical graphite has recently become a subject of research. For instance, graphite is mildly oxidized by catalytic oxidation [1-3], air [4-6], oxygen, carbon dioxide [7], solution of $\mathrm{H}_{2} \mathrm{O}_{2}, \mathrm{Ce}\left(\mathrm{SO}_{4}\right)_{2}$ $[8,9]$, or fluorinated by fluorine gas [10-12]. It has other uses,

\footnotetext{
* Corresponding author. 245, Sec. 3, Yen-Chiu-Yuan Road, Nankang, Taipei 115, Taiwan, ROC. Tel.: +886227867048x26; fax: +886227867253.

E-mail address: yswu@cc.chit.edu.tw (Y.-S. Wu).
}

such as epoxy resin coating [13], ionic conductive copolymer [14], oxidative solutions [15,16], silver deposition [17] or mechanical milling [18]. Other carbonaceous materials can also be deposited by thermal vapor deposition (TVD) on the surface of graphite pitch coke, phenol-formaldehyde resin and pyrolysis carbon [19], The complexity of research and development increased as new carbon coating methods are developed.

In this work, phenol resin is used as a carbon coating material. The phenol resin after heat-treatment will be changed into hard carbon that covers the spherical graphite surface. Phenol resin pyrolyzes upon heating to the glass-transition-temperature. It floats well and exhibits favorable chemical properties. Carbon coating and improved performance are expected herein to reduce the decay in the battery capacity. The use of modified spherical graphite is expected to increase the competitiveness of commercial anode electrode production.

\section{Experimental}

\subsection{Powder preparation}

The spherical natural graphite used herein was from Mainland China. The original natural graphite flakes from the jet miller were spread to spherical graphite. The phenol resin was obtained from Kuen Bong Chemical Industry Corp. Taiwan. 0, 10, 25 and $45 \mathrm{wt} \%$ phenol resin were blended with spherical natural graphite. The powders were code-named as NG0, NG10, NG25 and 
NG45, respectively. The blended powders were mixed into the methyl alcohol solvent for $30 \mathrm{~min}$ with a magnetite agitator. At room temperature, drying totally volatilizes methyl alcohol to form slurry powder. The phenol resin/spherical graphite precursor powders were placed in a tube furnace with nitrogen, and then heated to $1100^{\circ} \mathrm{C}$ at a heating rate of $10^{\circ} \mathrm{C} / \mathrm{min}$ at which they were soaked for $5 \mathrm{~h}$. Phenol resin/spherical graphite composite powders were produced after grinding and sieving through a 400 mesh. The FEG-SEM, X-ray diffraction and charge/discharge testing were employed to verify the structural characteristics of the carbon-coated graphite.

\subsection{Electrode preparation}

Anode electrodes were prepared using poly-vinylidene fluoride (PVDF) as a binder and $n$-methyl pyrolidinone (NMP) as a solvent. The mixture was mixed uniformly by agitation for $15 \mathrm{~min}$. The slurry powders were deposited onto a copper foil substrate to a thickness of $200 \mu \mathrm{m}$. The remaining solvent was removed by baking at $90^{\circ} \mathrm{C}$ in vacuum.

\subsection{Battery assembly}

The rolled film was cut into $1 \mathrm{~cm}^{2}$ circle plates, and used as the anode electrode. The cathode was lithium metal foil. The electrolyte solution was $1 \mathrm{M}$ $\mathrm{LiPF}_{6}$-EC/EMC (1:2 by vol.). Coin cells were assembled under atmospheric conditions in a dry room. The electrochemical characteristics were determined from the galvanostatic discharge/charge cycle, corresponding to a rate of $\mathrm{C} / 10$ between 0 and $1.8 \mathrm{~V}$ versus $\mathrm{Li} / \mathrm{Li}^{+}$.

\section{Results and discussion}

\subsection{X-ray diffractometry $(X R D)$}

Fig. 1 indicates that the characteristic natural graphite peak with $42.5^{\circ} \mathrm{H}(100)$ and $44.5^{\circ} \mathrm{H}(101)$ has a hexagonal structure,

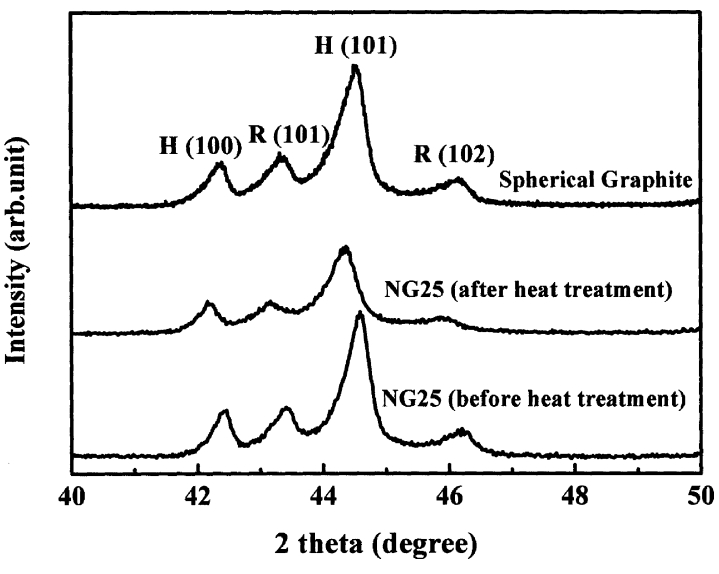

Fig. 1. XRD of spherical natural graphite and carbon-coated graphite with $25 \mathrm{wt} \%$ phenol resin (NG25) by heat-treatment at $1100^{\circ} \mathrm{C}$.

and that with $43.5^{\circ} \mathrm{R}(101)$ and $46^{\circ} \mathrm{R}(102)$ has a rhombohedral structure. The hexagonal structure peak intensity tends to decline and the rhombohedral peak intensity increases as the amount of phenol resin is increased. The phase peak intensities in Fig. 1 reveal that phenol resin decomposes to amorphous hard carbon at high temperature as the thickness of the carbon coating increases. The amount of crystalline graphite decreases as more carbon is coated onto the graphite surface. As the carbon coating weight percentage increases, the coverage of the surface increases and the peak at the $\mathrm{H}(100)$ and $\mathrm{H}(101)$ decreases. Graphite crystallization declines after the weight percentage increases. Fig. 1 shows that graphite NG0 has the highest
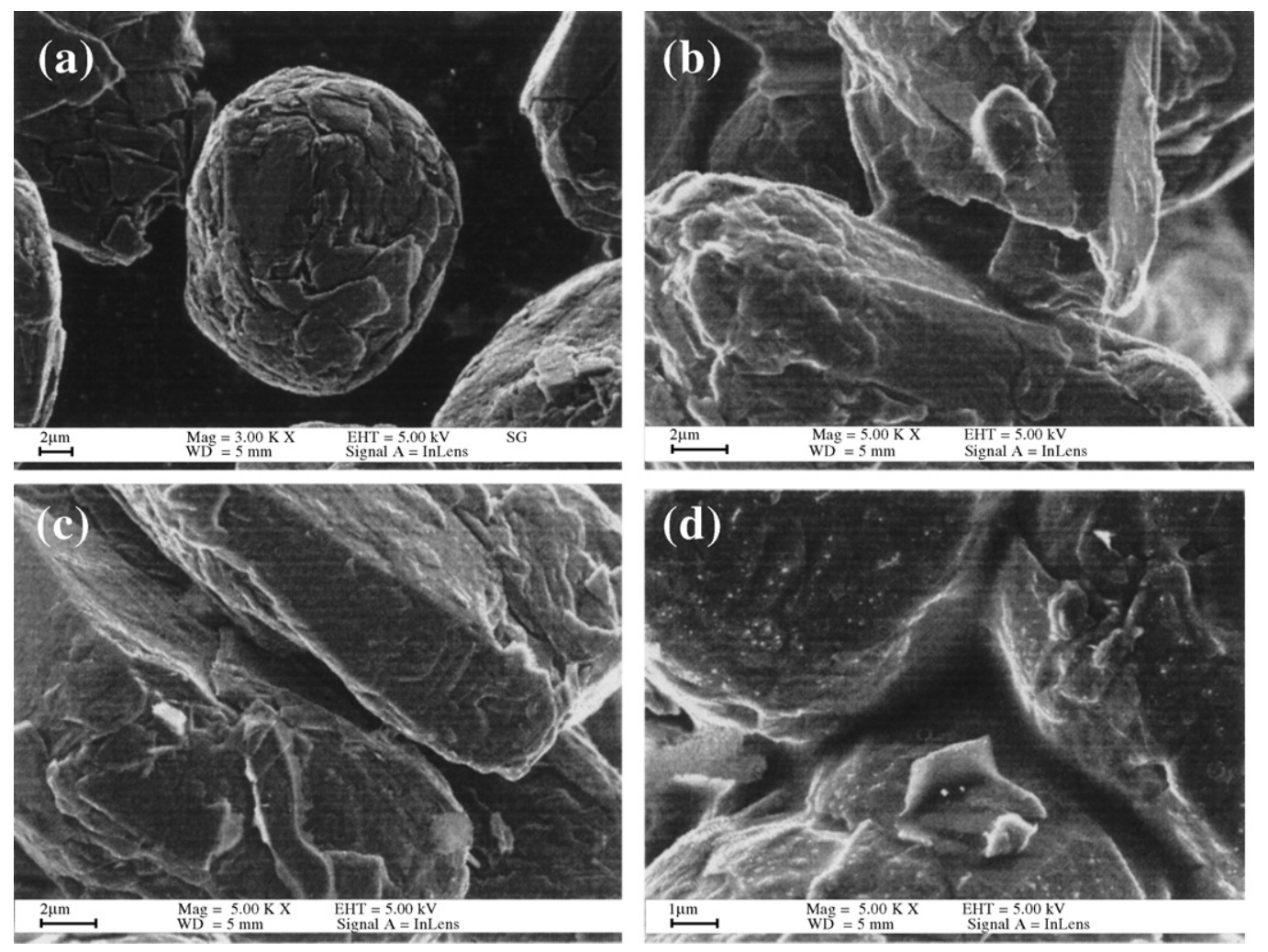

Fig. 2. SEM of graphite samples (a) NG0. (b) NG10. (c) NG25. (d) NG45. 
level of crystallization. As the carbon coating weight percentage increases to $25 \mathrm{wt} \%$, the degree of crystallization decreases. As the coverage of the carbon coating increases, the phenol resin decomposes the amorphous hard carbon, reducing the crystallization degree of the graphite.

\subsection{Scanning electron microscope (SEM)}

Fig. 2(a)-(d) presents the SEM pictures of carbon coating. Fig. 2(a) shows an SEM photograph of spherical natural graphite. The mechanical stress caused by jet milling establishes a sphere-like morphology. The sizes of the particles are acceptable. The particles are approximately $35 \mu \mathrm{m}$ in size and are uniformly distributed.

The morphology changes after the carbon coating as presented. The $10 \mathrm{wt} \%, 25 \mathrm{wt} \%$ and $45 \mathrm{wt} \%$ carbon-coated samples are prepared by heat-treatment at $1100^{\circ} \mathrm{C}$ for $5 \mathrm{~h}$ in a tube furnace. Fig. 2(b) demonstrates that the powders with fewer agglomerations in coating $10 \mathrm{wt} \%$ coating than in the other coatings. Organic polymers are present among the particles. The coverage increases with the weight percentage. The particles are sized from $30 \mu \mathrm{m}$ to $100-1000 \mu \mathrm{m}$, and the agglomeration is more severe.

\subsection{Raman spectroscopy}

Fig. 3(a) presents the Raman spectra of phenol resin on spherical natural graphite. The graphite characteristic peak of the $\mathrm{G}$-band was at around $1580 \mathrm{~cm}^{-1}$. The diamond or carbon characteristic peak of the D-band was at around $1360 \mathrm{~cm}^{-1}$. The intensity of the peak at $1580 \mathrm{~cm}^{-1}$ tends to drop as the amount of added phenol resin increases. The intensity of the peak at $1360 \mathrm{~cm}^{-1}$ remains constant at low concentrations. The characteristic peak at $1580 \mathrm{~cm}^{-1}$ becomes stronger at $1360 \mathrm{~cm}^{-1}$ as the added amount is increased to $15 \mathrm{wt} \%$, indicating that graphite exhibits higher graphitization upon the addition of less phenol resin is added. As the added amount increases, the phenol resin decomposes into hard carbon, which in turn increases the amount of amorphous carbon. Therefore, the graphitization of the carbon-coated graphite decreases as the amount of coke increases.

Fig. 3(b) plots the specific value of the Raman characteristic peak intensity. It is defined as $R$-value $=\left(I_{1360}\right) /\left(I_{1580}\right)$. A larger $R$-value shows that the D-band intensity is more obvious with the added phenol resin. This is a standard index of the amount of carbon coating [20-22]. This picture demonstrates that the $R$-value is 0.07 when the phenol resin approaches $10 \mathrm{wt} \%$. The $R$-value increases to 0.46 as the amount of phenol resin increases to $45 \mathrm{wt} \%$, and the carbon coating on the graphite surface is thickened.

\subsection{Charge-discharge test}

The charge-discharge test was performed to plot the voltage versus the capacity. Fig. 4(a) presents the bare spherical natural graphite charge-discharge results. The first discharge capacity approaches $350 \mathrm{mAh} / \mathrm{g}$, whereas the first irreversibility is almost
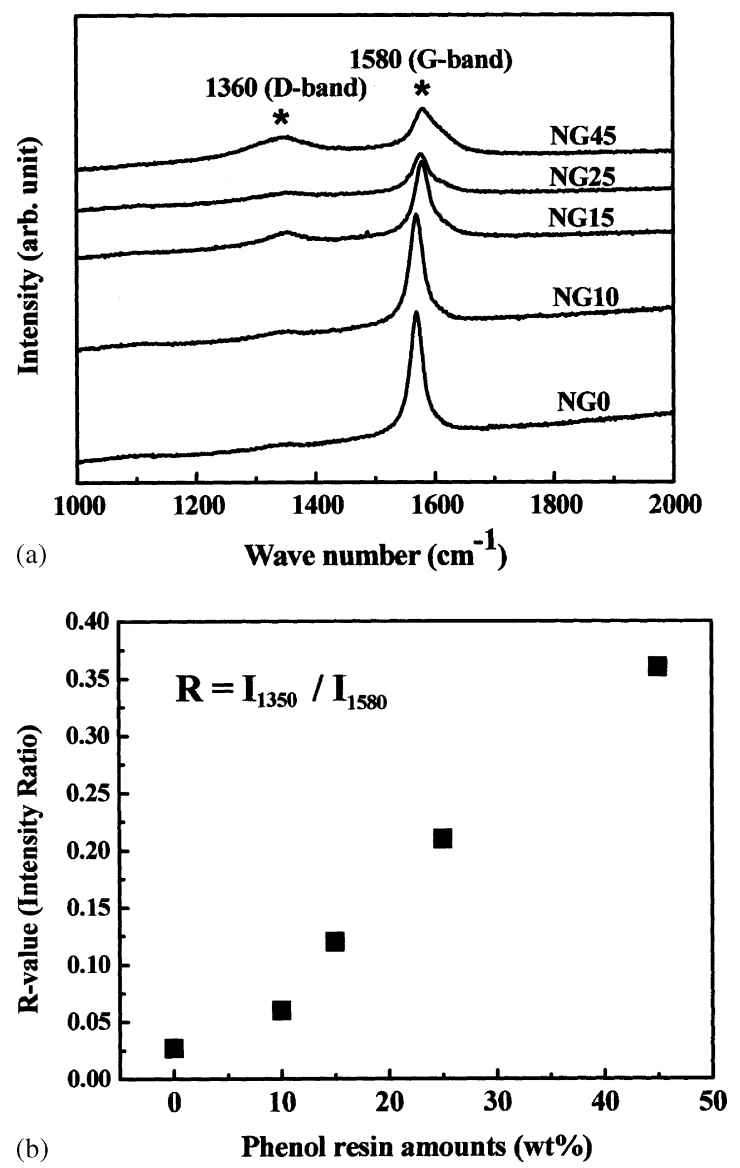

Fig. 3. Raman spectra and $R$-value of spherical graphite. (a) Adding different amounts of phenol resin. (b) $R$-value of spherical graphite obtained by adding different phenol resins.

$14.3 \%$, which is close to that of the commercial anode material MCMB, with a value of $10 \%$. However, as the duration for the charge-discharge cycle increases, the capacity decays severely. On the fifth test, the capacity has already decayed to $200 \mathrm{mAh} / \mathrm{g}$, indicating the bare spherical graphite, which facilitates the penetration of the lithium ion insertion while lithium ion is initially stored in the first cycle. Clearly, the capacity is the highest during the first charge-discharge cycle. However, the capacity decays seriously as the duration of the charge-discharge cycle increases. The spherical graphite structures are probably not very tough. The lithium ion can no longer be inserted, causing serious capacity decay.

Fig. 4(b)-(d) and Table 1 demonstrate that the capacity increases with the carbon coating. After the fifth charge-discharge cycle, the charge capacity of the carbon coating $10 \mathrm{wt} \%$ decreases to $291 \mathrm{mAh} / \mathrm{g}$ and that at $25 \mathrm{wt} \%$ decreases to $342 \mathrm{mAh} / \mathrm{g}$. When the amount of phenol resin added was increased to $45 \mathrm{wt} \%$, the charge capacity approached $372 \mathrm{mAh} / \mathrm{g}$, indicating good stability during the charge-discharge cycle. The capacity drop in NG45 was improved. The first irreversibility of the spherical natural graphite and the carbon-coated graphite does not significantly differ from NG0 to NG25 that presented in Table 1. Fig. 5 depicts the cycling behaviors of the discharge capacity of spherical nat- 

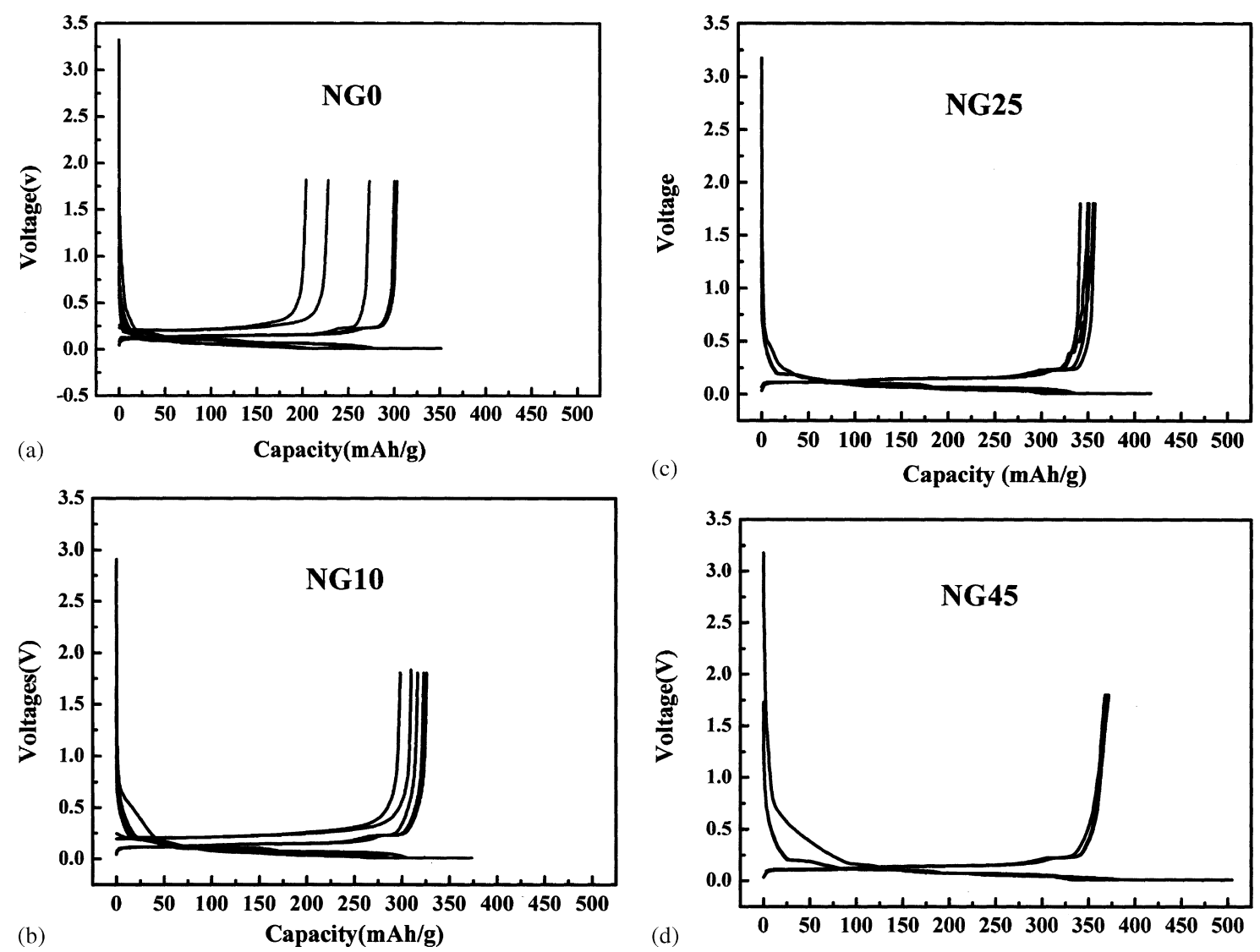

Fig. 4. Charge-discharge curves of spherical natural graphite and carbon-coated graphite in (a) NG0. (b) NG10. (c) NG25. (d) NG45.

Table 1

Charge-discharge characteristics of the spherical natural and carbon-coated graphite

\begin{tabular}{lllll}
\hline $\begin{array}{l}\text { Samples } \\
\text { name }\end{array}$ & $\begin{array}{l}\text { 1st discharge } \\
\text { capacity } \\
(\mathrm{mAh} / \mathrm{g})\end{array}$ & $\begin{array}{l}\text { 1st charge } \\
\text { capacity } \\
(\mathrm{mAh} / \mathrm{g})\end{array}$ & $\begin{array}{l}\text { 1st irreversibility } \\
(\%)\end{array}$ & $\begin{array}{l}\text { 5th charge } \\
\text { capacity } \\
(\mathrm{mAh} / \mathrm{g})\end{array}$ \\
\hline NG0 & 350 & 300 & 14.3 & 200 \\
NG10 & 373 & 317 & 15.0 & 291 \\
NG15 & 442 & 365 & 17.4 & 337 \\
NG25 & 417 & 358 & 14.1 & 342 \\
NG45 & 511 & 376 & 26.4 & 372 \\
\hline
\end{tabular}

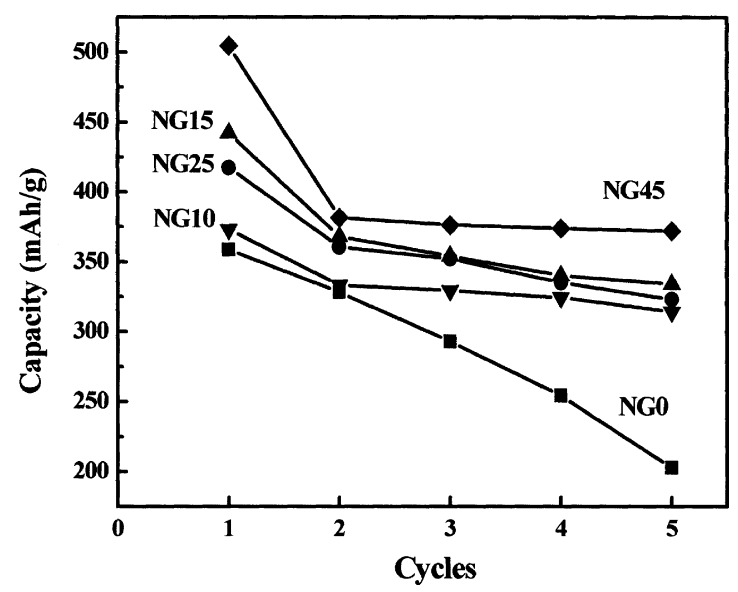

Fig. 5. Cycling behavior of discharge capacity of the spherical natural graphite and carbon-coated graphite. ural graphite and carbon-coated graphite. Heat-treatment with phenol resin and carbon coating improve the graphite structure. Modifying the surface of the graphite enhances the electrochemical performance and increases the stability of lithium ion batteries.

\section{Conclusions}

Carbon coating by heat-treatment at $1100^{\circ} \mathrm{C}$ with phenol resin improves the efficiency of spherical natural graphite. Amorphous carbon is formed on the graphite. This film inhibits the insertion of the lithium complex into the graphite interlayer, increasing the charge-discharge efficiency. The first charge capacity approaches $376 \mathrm{mAh} / \mathrm{g}$ when the amount of added phenol resin is $45 \mathrm{wt} \%$. The stability of the capacity is effectively maintained after the fifth charge-discharge test. Surface modification enhances the storage of lithium ions, increasing the capacity. Carbon coating on the graphite surface causes the SEI to be smooth following the first charge-discharge cycle, improving the stability and cycle life of the battery.

\section{Acknowledgements}

The authors would like to thank the National Science Council of the Republic of China, Taiwan, for financially supporting this research under Contract No. NSC 92-2218-E-157-003. 


\section{References}

[1] Y. Wu, C. Jiang, C. Wan, E. Tsuchida, Electrochem. Commun. 2 (2000) 272.

[2] S.G. Oh, R.J. Baker, J. Catal. 128 (1991) 137.

[3] R.B. Bjorklund, C.U. Odenbrand, G.M. Bundim, A.H. Anderson, B. Lienderberg, J. Catal. 119 (1989) 201.

[4] Y.P. Wu, C. Jiang, C. Wan, R. Holze, Solid State Ionics 156 (2003) 283.

[5] C. Menachem, Y. Wang, J. Floners, E. Peled, S.G. Greenbaum, J. Power Sources 76 (1998) 180.

[6] T. Takamura, H. Awano, T. Ura, K. Sumiya, J. Power Sources 68 (1997) 114.

[7] H. Buqa, P. Golob, M. Winter, J.O. Besenhard, J. Power Sources 97/98 (2001) 122.

[8] Y.P. Wu, C. Jiang, C. Wan, E. Tsunchida, Electrochem. Commun. 11 (2001) 1233.

[9] Y.P. Wu, C. Jiang, C. Wan, R. Holze, E. Tsunchida, Electrochem. Commun. 4 (2002) 483.

[10] T. Nakajima, V. Gupta, Y. Ohzawa, M. Koh, R.N. Singh, A. Tressaud, E. Durand, J. Power Sources 104 (2002) 108.
[11] T. Nakajima, M. Koh, R.N. Singh, M. Shimada, Electrochim. Acta 44 (1999) 2879.

[12] Y. Matsuo, M. Segawa, J. Mitani, Y. Sugie, J. Fluorine Chem. 87 (1998) 145

[13] W.H. Qiu, G. Zhang, S.G. Lu, Q.G. Liu, Solid State Ionics 121 (1999) 73.

[14] Q.M. Pan, K.K. Guo, L.Z. Wang, S.B. Fang, Solid State Ionics 149 (2002) 193.

[15] S.S. Zhang, K. Xu, T.R. Jow, J. Power Sources 129 (2004) 275.

[16] Y.P. Wu, C. Jiang, C. Wan, R. Holze, J. Power Sources 111 (2002) 329.

[17] Y.P. Wu, C. Jiang, C. Wan, R. Holze, J. Power Sources 112 (2002) 255.

[18] H. Wang, T. Ikeda, K. Fukuda, M. Yoshio, J. Power Sources 83 (1999) 141.

[19] M. Yoshio, H. Wang, K. Fukuda, Y. Hara, Y. Adachi, J. Electrochem. Soc. 147 (4) (2000) 1245.

[20] K. Suzuki, T. Hamada, T. Sugiura, J. Electrochem. Soc. 146 (1999) 890.

[21] T. Nakajima, M. Koh, R.N. Singh, M. Shimada, Electrochim. Acta 44 (1999) 2879.

[22] T. Tsumura, A. Katanosaka, I. Souma, T. Ono, Y. Aihara, J. Kuratomi, M. Inagaki, Solid State Ionics 135 (2000) 209. 